\title{
Halstar: systems engineering for sustainable development
}

1 Oliver J. D. Pearce MEng, EngD, CEng Research Engineer in Sustainable Systems, Halcrow Group Ltd and University of Bristol, Bristol, UK

2 Nicholas J. A. Murry MSc, PhD, PGDip Env Policy Associate Director and Group Manager for Sustainable Development, Halcrow Group Ltd, Bristol, UK
3 Timothy w. Broyd BSC, PhD, CEng, FREng, FICE, FRSA Group Director of Technology and Innovation, Halcrow Group Ltd, Bristol, UK
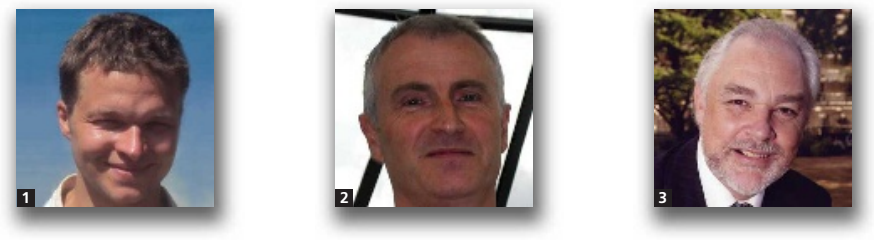

Sustainable development is subjective and value laden, and achieving it involves balancing a complex system of issues. Most existing approaches to assessing and managing sustainability fail to address sustainability in the particular context of a project and its stakeholders. A more holistic, 'systems approach' is required to address sustainability effectively. The Halcrow sustainability toolkit and rating (Halstar) system has been designed to provide a truly holistic methodology, incorporating many of the features of existing approaches, while attempting to mitigate their disadvantages. Halstar provides a common framework to support decision-making, enabling the comprehensive assessment and management of sustainable development issues. The technique works to improve sustainability on projects and programmes by guiding decision-making and appraisal within unique contexts and priorities. It ensures that sustainability, rather than being an add-on to the development process, becomes a source of added value. This paper outlines the rationale behind the development of Halstar and includes a case study demonstrating one of the ways it can be applied.

\section{Introduction}

The construction industry has a major role to play in achieving sustainable development - the built environment that is created has a significant influence on the structures and systems within which everyone operates. Infrastructure consultancies, such as Halcrow, have an opportunity to make a significant contribution to sustainable development through the services they provide in sectors such as civil engineering, buildings, transport, water and energy, from planning to design and supervision of construction.

Addressing sustainability in such a wide range of contexts can be highly complex, but this diversity also offers potential advantages to multidisciplinary consultancies, which are able to drive change by applying the kind of holistic understanding and multiple disciplinary input required.

While a plethora of approaches exists for assessing, managing and delivering sustainable development, few techniques are capable of addressing sustainability effectively in the specific context of a project and its stakeholders, while at the same time being applicable to the wide range of different contexts referred to above.

Through collaborative research being conducted by the University of Bristol's EngD Centre in Systems and Halcrow, substantial time and investment has been made in developing an innovative, systems-based, context-driven sustainability appraisal and management tool, the Halcrow sustainability toolkit and rating (Halstar), in order to address this challenge.

\section{The challenge of sustainable development}

\subsection{Defining sustainability}

The concept of 'sustainable development' and associated 'sustainability' is intrinsically value laden and open to interpretation (Fenner et al., 2006) and the terms are used with varying degrees of subjectivity, flexibility and even 
Engineering Sustainability

Volume 165 Issue ES2
Halstar: systems engineering

for sustainable development

Pearce, Murry and Broyd insincerity (Kates et al., 2005). Given the enormity of the challenge in balancing human and economic development with environmental limits, some commentators have gone as far as to describe the very term 'sustainable development' as an oxymoron: fundamentally contradictory and irreconcilable (e.g. Redclift, 2005).

While organisations in many sectors have a growing awareness of the need to become more sustainable, there are numerous different models and interpretations of what this means in practice, with as many as 300 different definitions already in circulation over a decade ago (Dobson, 1996). Clearer definitions have consequently been sought, appraisal methods developed and rating systems promoted, in an attempt to establish what needs to be done and to demonstrate that it has been done.

The most widely quoted definition of 'sustainable development' is probably that framed by the Brundtland Commission, as being development that "meets the needs of the present without compromising the ability of future generations to meet their own needs' (UN, 1987). While laudable in intent and underpinnings, the 'Brundtland definition' has been described as being sufficiently vague to justify a wide range of positions, without really challenging the existing market economic paradigm, or 'business as usual' to any significant extent (Ross, 2009).

Conceptual 'working definitions' include the 'three pillars' (UN, 2005) (Figure 1), a term introduced by the World Business Council for Sustainable Development and the 'triple bottom line' as promoted by John Elkington (1999). Arguably, these approaches have reinforced the tendency to treat the environment as a source of capital that is interchangeable with man-made capital, paying insufficient attention to environmental limits and treating sustainable development as a 'tradeoff' between the social, economic and environmental.

Springet (2003) contends that: 'the business discourse postBrundtland (1987) and at UNCED (1992)... largely sought to tame the concept to mean no more than a level of social and

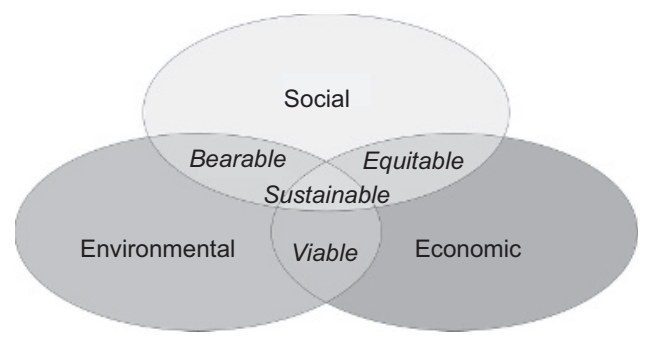

Figure 1. The three pillars of sustainability environmental engagement that corporations can easily accommodate or even use to burnish their brand. The result has been the accommodation of a potentially radical concept into what has been termed "eco-modernism".' In Springet's view, this eco-modernist paradigm deflects demands for the kind of radical change that is needed, interpreting sustainability as mainly concerned with organisational risk and resource efficiency, subsuming it into the traditional business model - essentially 'greener business as usual'.

Attempts at defining sustainability more robustly consider the economy and society as bounded by the environment, thereby acknowledging that the economy is a subsystem of the environment and the environment places limits on development (Figure 2).

In the words of Jonathon Porritt 'The economy is, in the first instance, a subsystem of human society... which is itself, in the second instance, a subsystem of the totality of life on Earth (the biosphere). And no subsystem can expand beyond the capacity of the total system of which it is a part.' (Porritt, 2006). The 'five capitals' model (Forum for the Future, 2011) takes the notion a step further by employing the concept of wealth creation or 'capital', from which society's and organisations' benefits are derived. Sustainable development requires maintaining and, whenever possible, enhancing these stocks of capital in an integrated way, so as not to destroy the natural capital upon which all other capitals depend (for more information see Forum for the Future, 2011) (Figure 3).

The model is closely related to the concept of 'strong sustainability' (Beckerman, 1994; Turner, 1992), which emphasises the importance of natural capital, attaching economic value to conserving future resources (including the earth's atmosphere) and recognising its critical importance. By this concept, critical natural resources (capital) cannot be substituted for

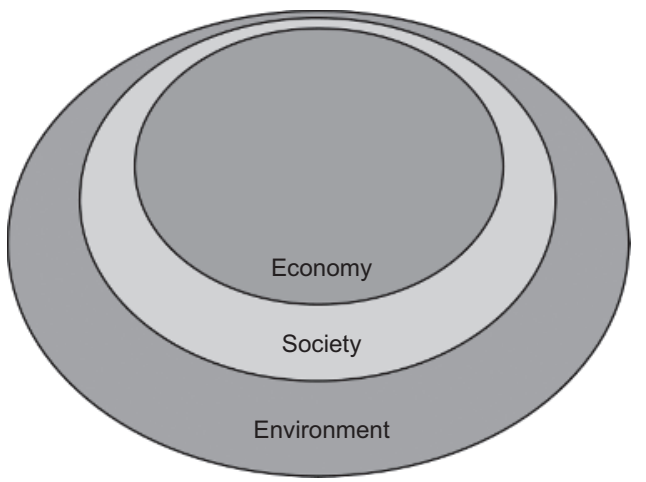

Figure 2. An alternative depiction of the three pillars 
Engineering Sustainability

Volume 165 Issue ES2
Halstar: systems engineering

for sustainable development

Pearce, Murry and Broyd

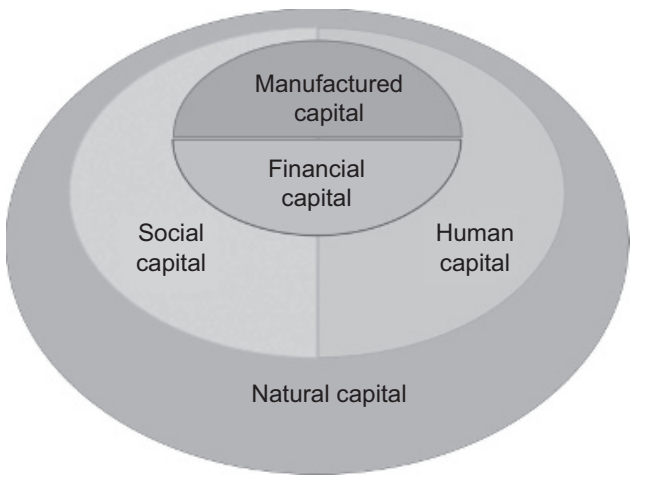

Figure 3. The five capitals model (Source: Forum for the Future, 2011)

other forms (although other forms of capital may be substituted for each other, as long as overall capital is enhanced). Critical environmental assets could be categorised as those that provide unique and essential services (such as life-supporting ecosystem services) or unique and irreplaceable non-use values (Ayres et al., 1998). 'Living within environmental limits' is also a key component of the UK Government's sustainable development strategy (Defra, 2005).

The concept of environmental limits is particularly relevant to the impact of greenhouse gas emissions on the earth's climate, described by Lord Stern as the 'the greatest and widest-ranging market failure ever seen', creating 'risks of major disruption to economic and social activity, later in this century' through changes that 'will be difficult or impossible to reverse' (Stern, 2006).

In view of the above, and in recognition of the importance of robust conceptual underpinnings, Halcrow has adopted Forum for the Future's five capitals model at the core of its strategic framework for sustainability (Forum for the Future, 2011), further developing the capitals in greater detail through the 12 areas shown in Figure 4.

\subsection{Appraising and managing sustainability}

There is a multitude of different methods for appraising sustainability. In the UK, these range from voluntary rating schemes such as Breeam (2009) and Ceequal (2009), through a range of public and private sector 'sustainability toolkits', to statutory processes such as sustainability appraisal, which is aimed at promoting sustainable development through the planning system and is mandatory in England and Wales under the Planning and Compulsory Purchase Act, 2004 (DCLG, 2004).

In general, rating systems are aimed at 'scoring' sustainability performance in specific contexts (e.g. the BRE Environmental

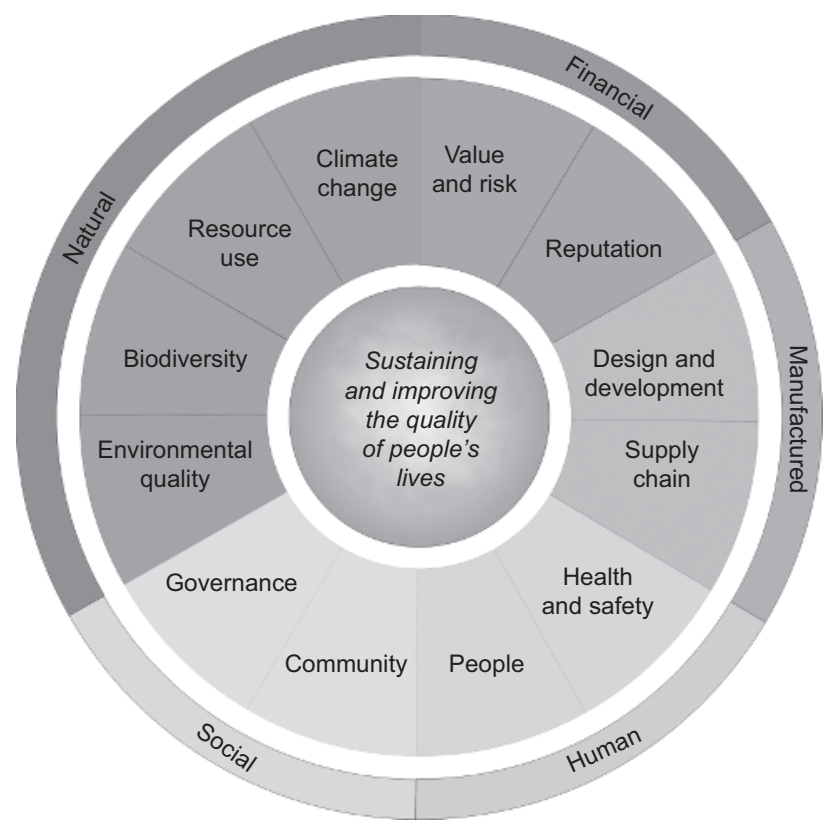

Figure 4. Halcrow's strategic framework for sustainability

Assessment Method (Breeam) in various building-related contexts and the Civil Engineering Environmental Quality Assessment and Award Scheme (Ceequal) in relation to civil engineering), whereas statutory sustainability appraisal and some of the private sector approaches have been developed to drive sustainability during the development of a plan or project, generally through application at a sufficiently early stage in the project cycle. Most approaches, including statutory sustainability appraisal, have tended to be relatively prescriptive (and long winded), yet limited in scope, and therefore constrained in terms of the value they can bring.

One of the better known private sector toolkits is Arup's SPeAR, originally developed in 2001. While SPeAR has been described as a holistic tool (EAP and Arup, 2009), it is essentially based on a number of widely accepted indicators, such as the index of corporate environmental engagement, the FTSE 4 good index, the UK Government's set of sustainability indicators and its sustainability strategy, United Nations Environment Programme indicators, and the global reporting initiative (McGregor and Roberts, 2003). As it does not encompass all of the issues that might be important in any given context, different versions have been developed for different contexts, hence the recent development of ASPIRE (EAP and Arup, 2009) for projects related to poverty reduction, for example.

Halstar was partly developed to overcome the perceived shortcomings of existing approaches. Key criteria in its development are as outlined below. 
Engineering Sustainability

Volume 165 Issue ES2
Halstar: systems engineering

for sustainable development

Pearce, Murry and Broyd
- A robust analytical approach: underpinned by a robust sustainable development paradigm, which recognises the importance of natural capital.

- Systems thinking (a holistic approach to problem solving that focuses on the relationships between elements within the context of larger systems, rather than addressing individual components in isolation): the use of a holistic, systems-based approach to analysis and the development of sustainable solutions.

- Stakeholder engagement: defining sustainability in terms of the material issues identified by stakeholders (in the widest sense), helping to ensure the appraisal is appropriate to any given context or scale.

- Effective communication: communicating the issues and appraisal results effectively to decisions-makers and stakeholders at appropriate stages of the project lifecycle.

- Flexibility: application at different levels of detail as required, across wide-ranging contexts.

Efficiency: recycling information and engaging relevant expertise, by combining a software-driven process with a database of reusable information, and links to available skills and experience.

Having noted Halstar's underpinning by the five capitals model, the authors will now expand upon the remaining criteria listed above.

\subsection{Systems thinking}

Sustainable development is complex and needs to be treated as such. It involves the integration of multiple disciplines in balancing a wide range of issues, with different stakeholder requirements and priorities, in a range of different contexts. The needs and values of different clients and sets of stakeholders can vary significantly between different market sectors, cultures and world regions.

A sustainable approach to construction has to be grounded in the unique project contexts that result from different client-led, local, national and international influences and priorities. The iterative interaction of these issues makes it difficult to take decisions with any certainty and can lead to potentially significant economic, social and environmental consequences.

Interpretations are rooted in people's perspectives and value systems, and these features make it difficult to formulate and justify apparently simple decisions (e.g. what is a 'good' solution?). Either the criteria on which decisions are taken do not adequately address the issues, or the way in which they address them is not acceptable to key stakeholders.

Such 'complex adaptive systems' (dynamic networks of interactions between autonomous components in which both individual and collective behaviour adapts to changes in surrounding contexts) have several key features that must be understood in order to achieve effective sustainable solutions: they are nested (every system has a boundary and a purpose within a larger system), subject to adaptation (systems change and maintain stability in response to feedback), and exhibit emergence (patterns emerge from interactions in the system). Sustainability can be described as an emergent property of complex systems - the overall sustainability of a project or process depends on the causal relationships between the issues and impacts involved in that context, and cannot be determined by looking at individual impacts in isolation (Elghali et al., 2008; Godfrey, 2006).

It is contended that no effective, fully integrated approach for managing sustainability in context currently exists (Thomson et al., 2009). Most assessment methods use a predefined checklist of requirements against which performance is measured. These methods define different sets of criteria and use inbuilt weightings (e.g. credits) to produce an overall score; they imply an objective, generally applicable definition of sustainability. This allows them to provide a simple rating that can be compared with similar projects, but this is achieved at the expense of context-driven requirements (Panagiotakopoulos and Jowitt, 2008). Therefore, irrational trade-offs can often be made in order to gain credits, key issues can be missed, and sustainability becomes an 'add-on' to the development process, rather than a potential source of added value.

With no common framework, decision-makers often have to start from scratch in establishing combined requirements from client briefs and strategy documents, rating schemes, regional and local policies and planning requirements, funding criteria and relevant legislation, in addition to developing 'sustainability criteria'. As most infrastructure systems are complex, addressing issues in isolation not only results in missed opportunities, but can also generate unintended consequences. A more holistic, 'systems approach', which takes account of how various elements of the system interact, provides a solid basis for addressing such problems more effectively (Godfrey, 2006).

\subsection{Stakeholder engagement}

Sustainable development depends upon the perceptions, desires and intentions of those affected and involved - the stakeholders. While the collation and interpretation of available evidence plays a fundamental role in sustainability appraisal, it is the stakeholders who essentially determine which issues are important and the extent to which they are significant. This includes collective positions expressed through policy and strategy, as well as the views of the client, end-users and wider society. 
Engineering Sustainability

Volume 165 Issue ES2
Halstar: systems engineering

for sustainable development

Pearce, Murry and Broyd
Most sustainability appraisal and management methods are limited in the extent of their engagement with stakeholders, constraining their ability to capture and deal with the full range of issues, limiting their potential value and increasing the risk of disagreement, objection or legal challenge (e.g. as was recently the case in relation to the sustainability appraisal for the East of England plan (Landmark Chambers, 2009)).

Capturing and communicating the range of positions and perspectives involved requires effective stakeholder identification, mapping and engagement, and a framework within which stakeholder perceptions and requirements can be systematically assessed and managed. Stakeholder priorities, appropriately weighted, will then help ensure sustainable solutions are achieved for the particular context under consideration.

\subsection{Effective communication}

A key aim of sustainability appraisal is to achieve an optimal sustainable outcome. Most of the methods reviewed by the authors appear to grapple with the challenge of providing clear, graphic summaries of results in a form that quickly conveys essential information in a consistent, digestible manner

For regulatory-driven appraisal methods such as statutory sustainability appraisal, output tends to be in the form of multiple matrices, often summarised in the main report, with greater detail provided in the appendices, none of which is particularly quick or easy for decision-makers to absorb.

Proprietary methods to date have attempted to address this issue in different ways but with varying levels of success. Sustainability appraisal and management methods could be made more effective (including in terms of the outcomes they influence) by paying greater attention to the effective communication of key findings to the key stakeholders and decisionmakers involved.

\subsection{Flexibility}

Most methods were designed with legislative-driven requirements or specific contexts in mind and can be very prescriptive (in terms of what sustainability means) as a result. They can also be limited in application to those contexts for which they were designed, often requiring new versions to deal with wider or differing contexts. Few, if any, existing sustainability appraisal or management methods are designed in a way that readily allows application across wide-ranging contexts, from high-level strategic planning to detailed development scheme level.

\subsection{Efficiency}

The efficiency of the process surrounding some sustainability appraisal methods has sometimes been called into question (e.g. statutory sustainability appraisal is often carried out by local planning authorities for planning documents that are tiered or in another way related, resulting in repetitive analysis and referencing). For its part, the government has attempted to reduce such inefficiencies - for example, by amending regulations in relation to the need for sustainability appraisal of supplementary planning documents (OPSI, 2009). Regional observatories have also had a role to play in providing access to key information/documentation. However, as far as the authors are aware, no approaches to sustainability appraisal incorporate a means of systematically storing and recycling information to increase the speed of appraisal and the number of appraisals achievable for a given set of resources.

The following sections of the paper discuss how Halstar has been developed and continues to evolve to address the issues above.

\section{Development of the Halstar framework}

Halstar has been designed to provide a truly holistic and integrated methodology, incorporating many of the features of existing approaches, while attempting to mitigate their disadvantages. The methodology is based on the systems model shown in Figure 5, which represents sustainable development as the balance between a range of needs (capitals), for a nested system of stakeholders, throughout the lifecycle of a project or process. This generic model can be applied to describe the sustainability of any system. The challenge has been to determine how this applies in practice - in unique project contexts.

The wide range of perspectives necessary to achieve sustainable development requires a framework within which different stakeholder requirements can be managed. The context implies that grounded theory (a qualitative research methodology in

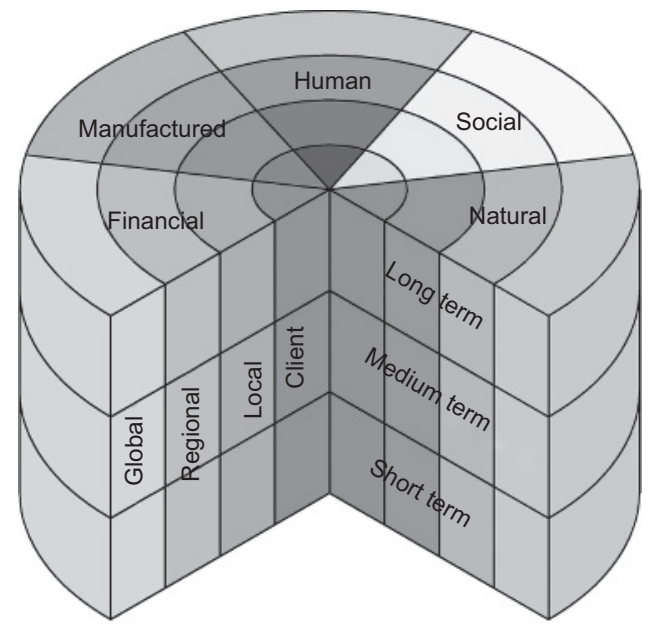

Figure 5. Systems model of sustainability 
Halstar: systems engineering

for sustainable development

Pearce, Murry and Broyd which theory is generated from the data, rather than the other way around) could be an appropriate methodology to understand the 'meanings and concepts used by social actors in real settings' (Gephart, 2004). The approach involves iterative data collection and analysis, and the construction of analytical codes and concepts from the data, with constant comparison and theory development at each stage of the analysis (Fendt and Sachs, 2008).

Based on the 12 areas in Halcrow's strategic approach, the Halstar sustainability wheel (Figure 6) is grounded in the definitions implicit in over 350 existing approaches, including assessment methods, indicator sets, legislation, planning policies, corporate responsibility reports and the requirements of key stakeholder groups.

The 'issues framework' (Figure 7) adds another dimension that of the cylindrical systems model. Issues in the diagram are associated with stakeholders on different scales: the client, project, end users, and local, regional and global impacts. At present, the resultant database of generic sustainability requirements contains approximately 840 subissues, with approximately 4200 qualitative criteria and 2000 different indicators identified at the next level down in the hierarchy. The use of grounded theory has resulted in a shared 'world view' of sustainable development that connects high-level policy with project-level practice.

The framework provides a comprehensive but highly adaptable means of aligning relevant requirements, enabling the contextdriven appraisal of all of the key factors affecting the sustainability of a project or programme. It also facilitates decision support by providing key individuals with associated information on lessons learned and best practice guidance from multidisciplinary sustainability practitioners around the world - using global expertise to guide locally tailored solutions. The approach can also help to coordinate and integrate project team inputs and align their concerns and requirements.

\section{The Halstar process}

As discussed above, sustainability is largely subjective - to achieve sustainable development in context, it is necessary to
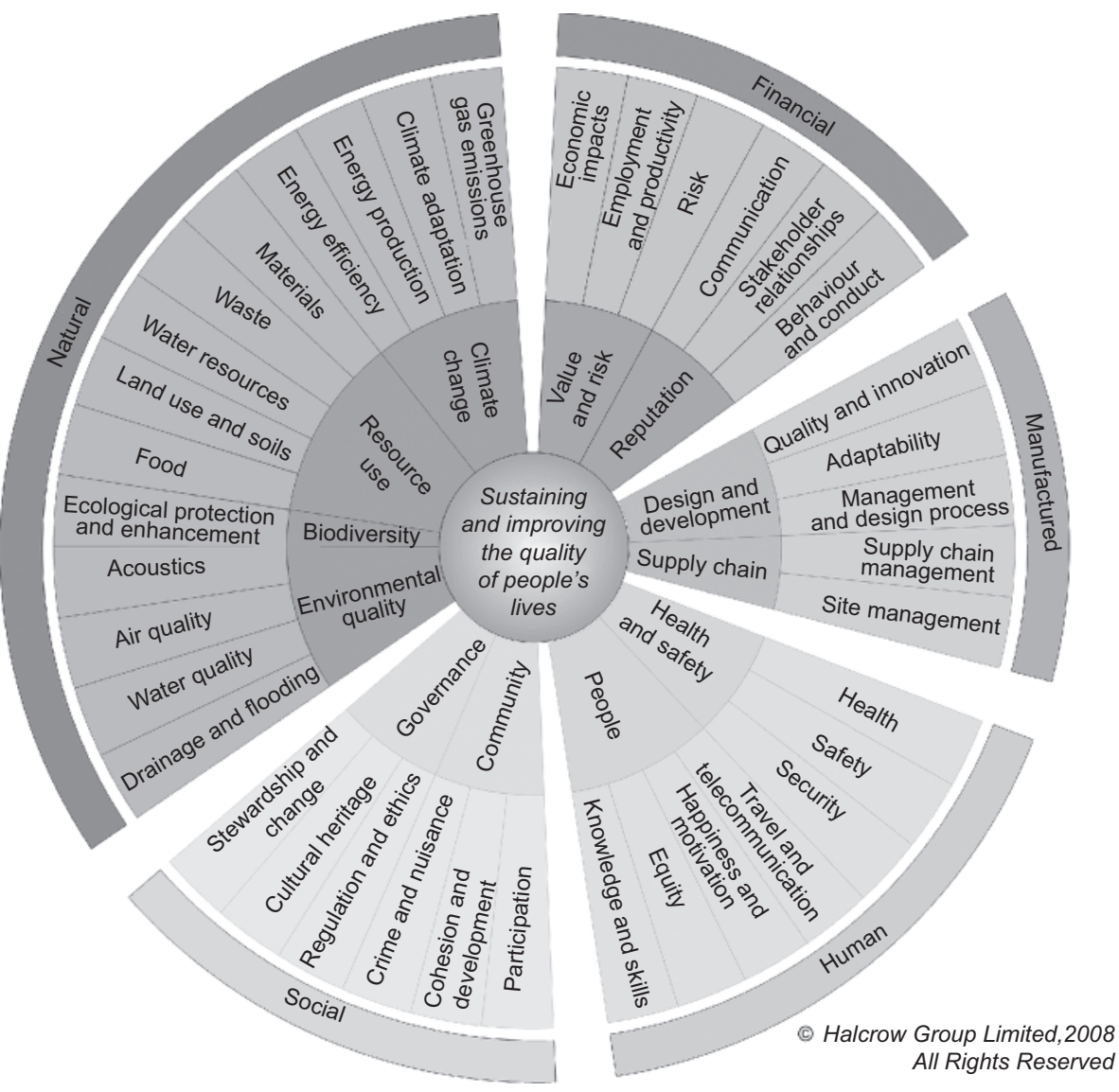

Figure 6. The Halstar sustainability wheel 


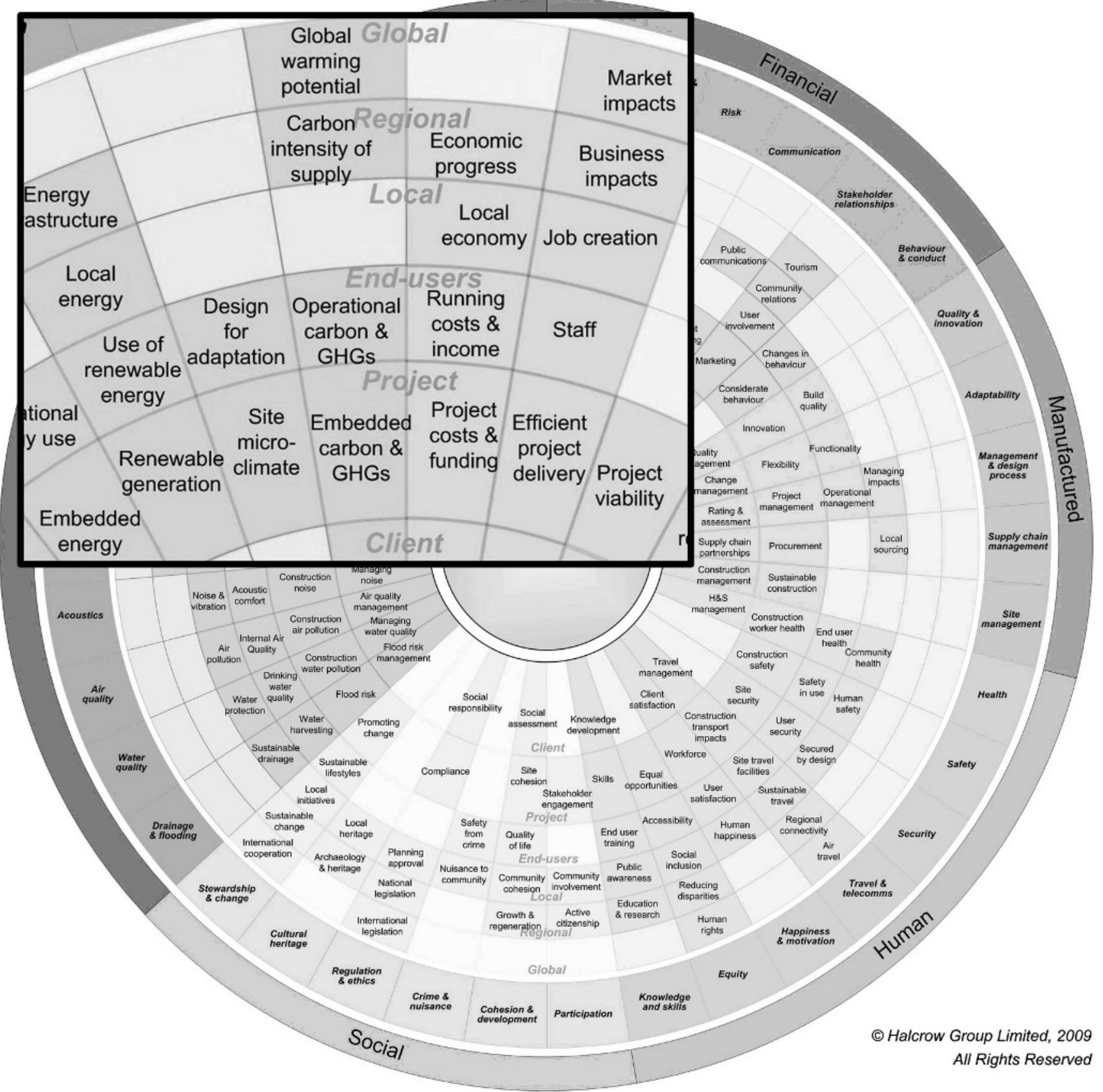

Figure 7. Halstar 'issues framework' with inset close-up

establish the needs and values of the stakeholders involved and the state of the surrounding 'systems'. While Halstar provides a holistic, generic framework, in order to be practically useful, it needs to be adapted to the context in question. This is achieved by managing relevant issues throughout the project lifecycle using the process shown in Figure 8 - an iterative loop of scoping, assessment, review and action. This is a bespoke process, and the elements used, the extent of their use and the number of iterations will depend on particular project requirements. As well as having the capability to conduct a detailed and iterative appraisal, the framework might simply be used to horizon scan for possible unintended consequences, or to carry out a gap analysis on previously identified project issues. 


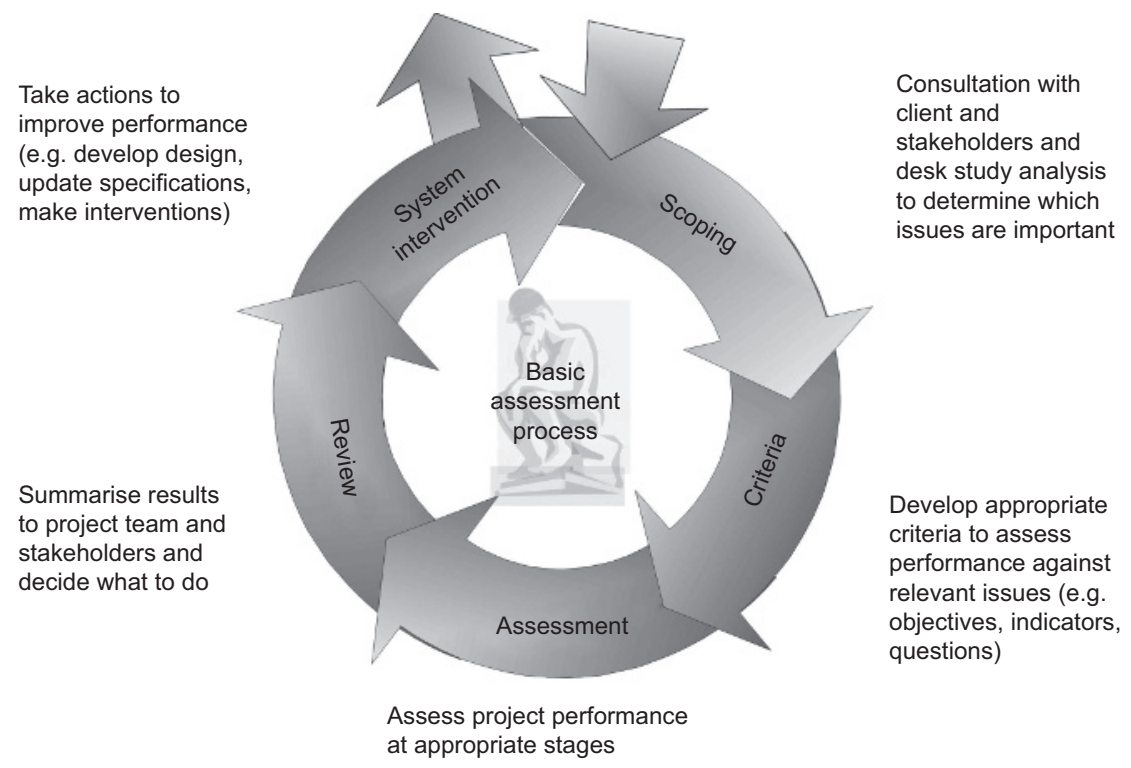

Figure 8. Basic Halstar process

\subsection{Scoping}

The scoping stage involves establishing which issues are relevant, through engagement with the client, stakeholders and project team; the Halstar framework is designed to align their concerns and requirements from the outset. Client requirements (e.g. invitation to tender, project brief, corporate plan), stakeholder needs (e.g. results of consultations, position statements), regulatory constraints (e.g. planning policy, national and international legislation, building regulations), and project-specific information (e.g. site surveys, design information and specifications) may all be included in this process.

Consultations are also used to establish the priorities of different groups and, when necessary, develop weightings to aggregate assessment results. Weightings developed through informed stakeholder consultation attain a measure of objectivity by triangulating multiple subjective opinions. Each discipline in the project team is likely to have to deal with numerous issues around the framework. It is important to ensure early project team involvement - the process can help to develop a shared vision, assign responsibilities and integrate design strategies.

\subsection{Assessment criteria}

Context-specific performance measures are developed on the basis of scoping information. Assessments are bespoke, guided by Halstar's framework. When appropriate, a mix of quantitative indicators and qualitative criteria may be used. Qualitative descriptions may be more appropriate in some cases, particularly with social considerations, when numbers can destroy meaning and may consequently be less valid and appropriate.

\subsection{Assessment and scoring}

Impacts on the client, end users, local area and wider environment are assessed by individuals with appropriate levels of expertise. Results of appraisals can then be conveyed to decision-makers and stakeholders at a resolution appropriate to their needs. The use of traffic-light scoring permits a rapid appraisal of the bigger picture, quickly highlighting problem areas, and enabling rapid comparison of options. Detailed output diagrams and supporting tables of criteria are based on unweighted scores. However, simplified diagrams involving aggregation can be produced that incorporate context-specific weightings developed during the scoping stage. Using these weightings, a multicriteria analysis can be conducted, which takes into account both the impacts of decisions on stakeholders and the importance that they assign to those impacts. When necessary, the use of causal loop diagrams can supplement this information, providing an understanding of the interactions between different issues.

\subsection{System interventions}

Once results have been summarised and reported, follow-up actions are agreed with the client and project team. This may involve development of the design, construction specifications, operations and maintenance clauses or other interventions depending on the type of project and stage in the lifecycle. The use of Halstar is driven by a software package that aids the 
Engineering Sustainability

Volume 165 Issue ES2
Halstar: systems engineering

for sustainable development

Pearce, Murry and Broyd provision of relevant information including best practice guidance, recommended strategies for improvement and case studies with lessons learned. Over time this will provide a knowledge bank through which practitioners can learn from each other. In doing so, it will improve the types of decision support available to help manage and proactively enhance project sustainability.

Upon completion of the project, post-occupancy evaluation, feedback on client and stakeholder satisfaction, and quantitative monitoring of resultant performance can be used to ensure feedback from real-world results is captured and compared with predictions. In this way, the system becomes an evolving process, learning from past problems and successes to deliver ever-improving results.

\subsection{Outcomes and benefits}

The authors' experience to date is that Halstar helps to make the complexity of sustainable developments easier to manage by splitting the issues into smaller, easily understood elements, and helping clients and decision-makers to understand what sustainability means in the context of their individual projects. It can complement and enhance existing methodologies such as Breeam, Ceequal and even statutory sustainability appraisal. It is also able to add value for clients by ensuring that all sustainability aspects are considered, while focussing on the key impacts and opportunities of their specific projects and programmes; reducing the risk of fines or delays associated with regulatory compliance by aligning and managing relevant requirements throughout the project, and flagging up issues at an early stage.

Through consideration of stakeholder needs and values in the development of context-specific performance measures and appraisal criteria, progress can be tracked to ensure stakeholder concerns are addressed effectively, helping to define priorities and enhancing clients' reputations.

The methodology also helps to identify innovative measures and key areas for action that will add value to the project, by improving lifecycle efficiency or reducing running costs, for example. The decision-support elements of the software help to ensure that Halcrow's global expertise can guide tailored solutions on a local level.

\section{Halstar in practice}

The methodology has been applied with public and private sector clients on projects ranging from eco-towns and mixeduse developments, flood defence schemes and shoreline management projects, to renewable energy projects, and has also been used to inform office relocation and ongoing internal operations. It is adaptable to any given context (including projects, products, processes and organisations) and is designed to mitigate risks and add value in that context. Potential applications range from simple options appraisals and monitoring frameworks to lifecycle asset management, corporate responsibility reporting and infrastructure programmes. In order to provide some context for the methodology, the following example demonstrates one way in which the approach has been used in practice. The authors intend to provide further examples of how Halstar has been applied in practice in a follow-up paper to be published at a later date.

In 2008, a study was undertaken for the Scottish Government to help the Western Isles to deliver economic and community benefit by identifying renewable energy potential compatible with environmental obligations. In order to ensure selected options were truly, not just economically, sustainable, Halstar was applied in conjunction with an appraisal of development options for onshore wind in North Lewis. In addition to the Scottish Government, key stakeholders included Scottish Natural Heritage, Scottish Environmental Protection Agency, Comhairle nan Eilean Siar and Highlands and Islands Enterprise. The needs and priorities of these stakeholders were integrated into appraisals by analysing a range of strategic policy documents to ascertain which issues were relevant. These included 'Creating communities of the future' (Comhairle nan Eilean Siar, 2008), the government economic strategy (Scottish Government, 2007a), 'Scottish planning policy 6: renewable energy' (Scottish Government, 2007b), national planning framework strategic environmental assessment guidance (SEPD, 2007), relevant Scottish Natural Heritage renewable energy policies (SNH, 2008), and funding criteria for the Scotland Rural Development Programme (SRDP, 2007).

Analysing these requirements and others against the Halstar framework highlighted key issues and priorities for the project, as shown by the highlighted segments in Figure 9. Context-specific criteria were then developed to ensure that options for wind farm locations would be appraised against appropriate stakeholder requirements. For example, criteria associated with 'business impacts' included requirements to create successful, competitive businesses with high productivity and to provide export opportunities, while those relating to 'impacts on surroundings' included promoting landscape management and planning, protecting and enhancing the quality, scenic value and distinctiveness of the landscape (SEPD, 2007; SRDP, 2007). The performance of each option against the full set of criteria was appraised by the Halstar assessor, and the results were peer-reviewed and updated as appropriate by a range of multidisciplinary specialists with knowledge of the area. The results of the options appraisal highlighted key differentiators between options (e.g. impacts on Natura 2000 sites and energy 


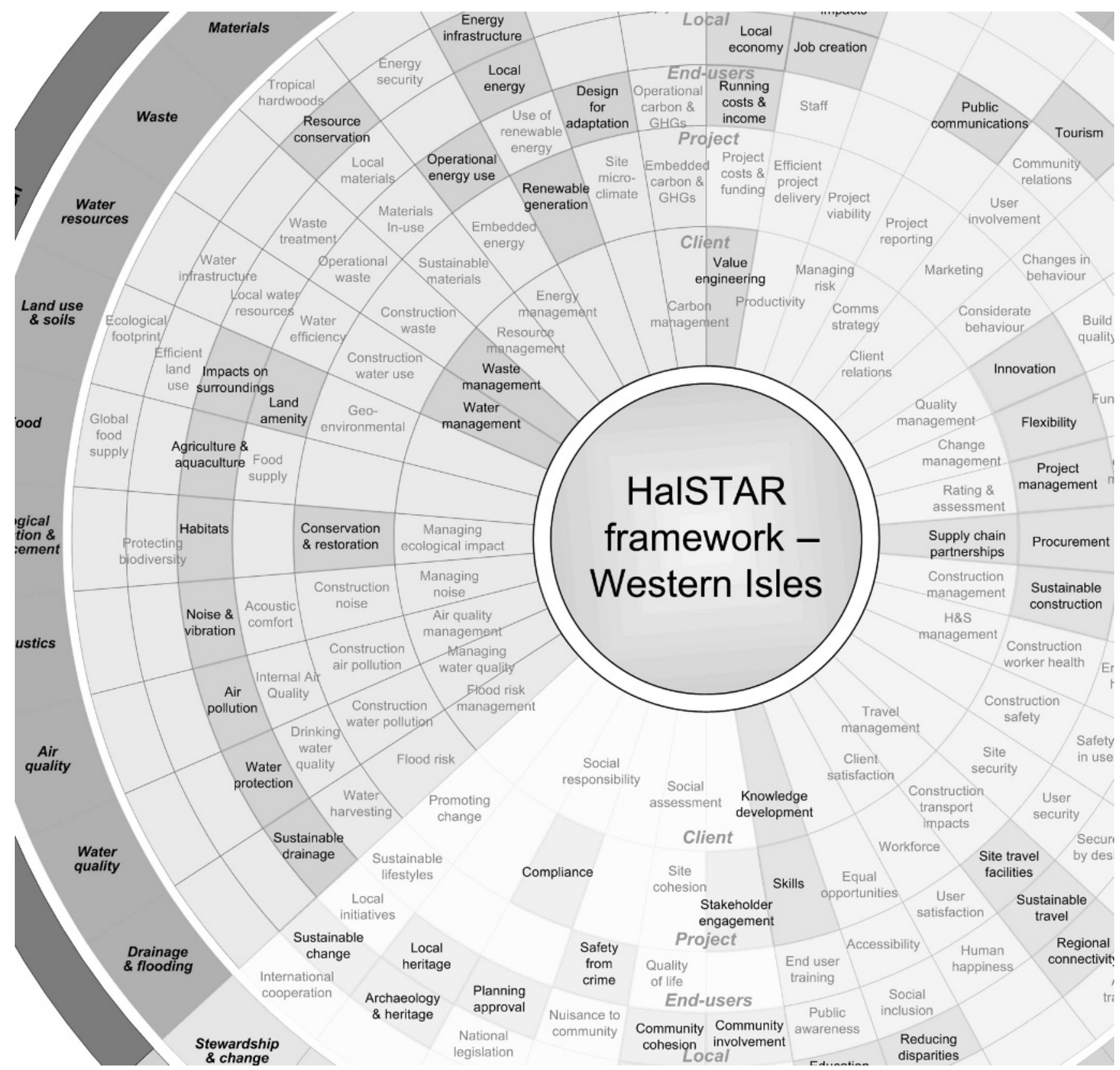

Figure 9. Relevant issues on the Western Isles project

infrastructure), aiding selection of the most appropriate way forward, while ensuring impacts were identified and mitigated effectively. The process facilitated the elimination of several options that would have significant negative impacts without providing additional benefits, and provided a transparent, auditable means of recommending options for further development, taking both local and national concerns and priorities into account. The full report is available on the Scottish Government website (Scottish Government, 2009).

\section{Evolution of the system}

The Halstar system will be continually revised and improved in order to ensure it becomes more efficient and effective in achieving its ultimate objective of delivering sustainable solutions. Knowledge management systems within the software have been designed to capture relevant information and lessons learned for use on future projects, while monitoring and feedback mechanisms will ensure that the approach continues to meet the needs of clients, decision-makers and other stakeholders as effectively as possible. 
Engineering Sustainability

Volume 165 Issue ES2
Halstar: systems engineering

for sustainable development

Pearce, Murry and Broyd
Successive versions of the software will incorporate a greater range of supplementary tools to support decision-making. Each of the issues in the framework can present a complex problem in its own right, but addressing these can impact on other issues, with possible adverse effects or unintended consequences. The systems thinking and engineering techniques inherent in the Halstar approach will be increasingly developed to deal with these tensions - treating the attributes and impacts of factors as part of an interacting whole and looking at the emergent properties of the system. System dynamics (a computer-aided modelling technique for defining and understanding the dynamic behavior of complex systems) methods will be used to build simulation models of these complex interactions, to allow decision-makers to predict outcomes under a range of scenarios and also to study their behaviour over time. This will allow results to be calibrated and validated against real-world impacts. Greater focus will also be given to developing optimal and informed solutions that allow clients and stakeholders to be clear about the implications of any proposed development.

Participative consultation with users, clients and other stakeholders will be essential throughout the development and implementation of the system. Halcrow is engaging and collaborating with a wide range of organisations in the public and private sectors, and will continue to do so, in order to ensure that the approach is as widely applicable and beneficial as possible.

\section{Conclusion}

Sustainable development is intrinsically value laden, and depends on the needs and values of the stakeholders involved. Addressing sustainability effectively in context can be highly complex, requiring the integration of multiple disciplines in balancing a wide range of interdependent issues. Most existing methods for assessing and managing sustainability are prescriptive, with limited identification of stakeholders' issues and a limited range of applicable contexts. Irrational trade-offs can be made, key issues overlooked and potential opportunities for sustainable solutions wasted.

This paper introduces a new, systems-based method, Halstar, which approaches these challenges by basing sustainable development on the definitions that are implied (but not always stated) in current approaches.

The Halstar framework provides a comprehensive but highly flexible means of understanding and managing requirements, enabling a stakeholder-based, context-driven appraisal of all of the key factors affecting the sustainability of a project or programme, while ensuring all potentially relevant issues are considered. It emphasises process efficiency (critical in terms of value and affordability), communicability (critical to influencing decision-makers and effecting change) and will increasingly focus on the development of systems-based solutions. The approach ensures that sustainability becomes a potential source of real added value, rather than being an add-on to the development process.

\section{REFERENCES}

Ayres RU, van den Bergh JCJM and Gowdy JM (1998) Viewpoint: Weak versus Strong Sustainability. Tinbergen Institute, Amsterdam, The Netherlands.

Beckerman W (1994) 'Sustainable development': is it a useful concept? Environmental Values 3(3): 191-209.

BREEAM (BRE Environmental Assessment Method) (2009) The world's leading design and assessment method for sustainable building. See http://www.breeam.org/ (accessed 10/01/2012).

CEEQUAL (Civil Engineering Environmental Quality Assessment and Award Scheme) (2009) CEEQUAL, the assessment and awards scheme for improving sustainability in civil engineering, infrastructure, landscaping and the public realm - celebrating the achievement of high environmental and social performance. See http://www.ceequal.org (accessed 10/01/2012).

Comhairle Nan Eilean Siar (2008) Creating Communities of the Future. Comhairle nan Eilean Siar, Stornoway, Isle of Lewis, Scotland.

DCLG (Department for Communities and Local Government) (2004) Planning and Compulsory Purchase Act, 2004. See http://www.legislation.gov.uk/ukpga/2004/5/contents (accessed 13/02/2012).

Defra (Department for Environment, Food and Rural Affairs) (2005) Securing the Future - UK Government sustainable development strategy. Defra, London, UK.

Dobson A (1996) Environment sustainabilities: an analysis and a typology. Environmental Politics 3(5): 401-428.

EAP (Engineers Against Poverty) and Arup (2009) ASPIRE Research and Development Manual. Engineers Against Poverty and Arup,

Elghali L, Clift R, Begg KG and Mclaren S (2008) Decision support methodology for complex contexts. Proceedings of the Institute of Civil Engineers: Engineering Sustainability 1(161): 7-22.

Elkington J (1999) Cannibals with Forks: The Triple Bottom Line of 21st Century Business. Capstone, Oxford, UK.

Fendt J and Sachs W (2008) Grounded theory method in management research: users' perspectives. Organizational Research Methods 3(11): 430-455.

Fenner RA, Ainger CM, Cruickshank HJ and Guthrie PM (2006) Widening engineering horizons: addressing the complexity of sustainable development. Engineering Sustainability ES4(159): 145-154.

Forum for the Future (2011) The Five Capitals Model: Project Overview. See http://www.forumforthefuture.org/project/ five-capitals/overview (accessed 10/01/2012). 
Halstar: systems engineering

for sustainable development

Pearce, Murry and Broyd
Gephart RP (2004) Qualitative research and the Academy of Management Journal. Academy of Management Journal 4(47): 454-462.

Godfrey P (2006) Systems thinking approach to sustainable innovation. In Joint International Conference on Construction Culture, Innovation, and Management (CCIM), Dubai.

Kates RW, Parris TM and Leiserowitz AA (2005) What is sustainable development? Goals, indicators, values, and practice. Environment: Science and Policy for Sustainable Development 3(47): 8-21.

Landmark Chambers (2009) East of England plan held to have breached SEA requirements. See http://www.

landmarkchambers.co.uk/news_events/news/five_ landmark_members_acting_in_challenge_to_the_east_ of_england_plan_on_sea_grounds (accessed 10/01/2012).

McGregor A and Roberts C (2003) Using the SPeAR Assessment Tool in Sustainable Master Planning. Arup,

OPSI (2009) Explanatory Memorandum to the Town and Country Planning (local development) (England) (Amendment) Regulations 2009, No. 401, paragraph 7.6. See http://www.opsi.gov.uk/si/si2009/em/uksiem_ 20090401_en.pdf

Panagiotakopoulos PD and Jowitt PW (2008) Sustainability assessment and reporting in property development: a case study. Engineering Sustainability ES1(161): 9399.

Porritt J (2006) Capitalism as if the World Mattered. p. 46. Earthscan, London, UK.

Redclift R (2005) Sustainable development (1987-2005): an oxymoron comes of age. Sustainable Development 13(4): 212-227.

Ross A (2009) Modern interpretations of sustainable development. Journal of Law and Society 1(36): 32 54.
Scottish Government (2007a) The Government Economic Strategy. Scottish Government, Edinburgh, UK.

Scottish Government (2007b) Scottish Planning Policy: SPP 6

Renewable Energy. Scottish Government, Edinburgh, UK. Scottish Government (2009) Economic and Community Benefit Study. Final report. Produced by Halcrow Group for Scottish Government. Halcrow Group Limited, Edinburgh, UK.

SEPD (Scottish Executive Planning Directorate) (2007) National Planning Framework, Strategic Environmental Assessment Stage 1: Assessment of Strategic Alternatives. SEPD, SNH (Scottish Natural Heritage) (2008) Renewable Energy SNH's Approach. See http://www.snh.org.uk/strategy/ renewable/sr-re01.asp

Springet D (2003) Business conceptions of sustainable development: a perspective from critical theory. Business Strategy and the Environment 12: 71-86.

SRDP (Scotland Rural Development Programme) (2007) Scotland Rural Development Programme 2007-2013: Rural Development Regulation (EC) No 1698/2005. Scottish Government, Edinburgh, UK.

Stern N (2006) Review on the Economics of Climate Change: H.M. Treasury, UK, October, 2006. See http://www. sternreview.org.uk

Thomson CS, El-Haram MA and Hardcastle C (2009) Managing knowledge of urban sustainability assessment. Engineering Sustainability ES1(162): 35-43.

Turner K (1992) Speculations on Weak and Strong Sustainability CSERGE Working Paper GEC 92-26. University of East Anglia, Norwich, UK.

UN (United Nations) (1987) Report of the World Commission on Environment and Development. UN, New York, USA.

UN (2005) 2005 World Summit Outcome, Resolution A/60/1, adopted by the General Assembly on 15 September 2005. UN, New York, USA.

\section{WHAT DO YOU THINK?}

To discuss this paper, please email up to 500 words to the editor at journals@ice.org.uk. Your contribution will be forwarded to the author(s) for a reply and, if considered appropriate by the editorial panel, will be published as discussion in a future issue of the journal.

Proceedings journals rely entirely on contributions sent in by civil engineering professionals, academics and students. Papers should be 2000-5000 words long (briefing papers should be 1000-2000 words long), with adequate illustrations and references. You can submit your paper online via www.icevirtuallibrary.com/content/journals, where you will also find detailed author guidelines. 